\title{
EL DELITO DE OMISIÓN. EN PARTICULAR, LA COMISIÓN POR OMISIÓN*
}

\author{
Raúl Carnevali Rodríguez \\ Profesor de Derecho penal \\ Universidad Católica del Norte (Sede Coquimbo) \\ Universidad de los Andes
}

\section{Introducción}

Me ha correspondido tratar el delito de omisión, centrándome de manera especial en lo que es la comisión por omisión, también denominada omisión impropia. No puedo dejar de reconocer que se trata de un desafío interesante, pues como se ha afirmado en la doctrina, se está frente a una de las áreas más difíciles de abordar, lo que ha suscitado una importante discusión teórica. Trataré pues, de exponer los aspectos más esenciales.

El problema central que tradicionalmente se presenta es el siguiente: cómo a un no hacer se le puede atribuir un resultado, esto es, cómo el no hacer podría causar naturalísticamente hablando - un determinado resultado.

Generalmente, y ahí esta la discrepancia en la doctrina como se expondrá más adelante, se ha entendido que gran parte de los figuras penales se construyen como tipos de comisión, es decir, sobre la base de un hacer activo. Por lo tanto, se presentarían serias dificultades para poder otorgar una relevancia jurídica a la omisión - un no hacer - frente a un determinado resultado. Como ya lo exponían los clásicos: ex nihílo nihil fit. A continuación, vamos a ver que resultan bastante discutibles esta clase de consideraciones ${ }^{2}$.

\footnotetext{
*El texto corresponde, salvo algunos agregados, a la conferencia ofrecida en la Escuela de Derecho de la Universidad Católica del Norte (sede Coquimbo) el día 4 de octubre de 2001, dentro del seminario "Cuestiones fundamentales de Derecho penal. Un análisis a la luz de la reforma al Código penal".

${ }^{1}$ Asi, CURY, Derecho penal, PG, T. II, $2^{\circ}$ ed., Santiago, 1992, p. 288, expresa se trata de uno de los sectores más oscuros de la estructura delictiva.

'Para GIMBERnAT ORDEIG, 'El delito de omisión impropia", en: Revista de Derecho penal y criminología, $n^{\circ} 4$, 1999, p. 533, el error de sostener que los tipos de lesión sólo se conciben para acciones, se debe, entre otros, a las opiniones de Radbruch y Armin Kaufmann.
} A 


\section{Comisión por omisión. Fundamento y alcance}

Como es sabido, el propio Art. 1 del Código penal hace una referencia expresa a las omisiones, castigando a éstas. Es decir, nos encontramos, tanto con normas prohibitivas como con normas de mandato.

Por su parte, en lo que a la omisión se refiere, se distingue entre lo que son las omisiones puras o propias y las omisiones impropias o comisión por omisión. Es del caso, que las primeras no presentan mayores dificultades, ya que se hallan expresamente tipificadas y no exigen la producción de un determinado resultado. Así, por ejemplo, el Art. 494 Nro. 14 del Código penal que dice relación con el delito de omisión de socorro, el que se funda esencialmente en razones de solidaridad. En este caso, la punición de la omisión recae sobre personas a las cuales no se les puede imputar la causación del proceso lesivo, pero sí tienen un deber de evitación, cuyo basamento, como ya se ha dicho, se halla en la solidaridad ${ }^{3}$.

No nos vamos a detener en esta clase de omisiones, pues no presenta los cuestionamientos teóricos que sí se manifiestan, como ya lo mencioné al inicio de esta conferencia, tratándose de la omisión impropia. $Y$ es que muchas de las críticas que se hacen a esta estructura normativa parten del supuesto de que ésta presentaría serios reparos desde la perspectiva del principio de legalidad. Tal es así, que una interesante sentencia de la Corte Suprema de 1998 se hace eco de esta clase de aprehensiones, al señalar que esta figura pone de manifiesto algunas reservas en el plano constitucional ${ }^{4}$.

${ }^{3}$ Como expone SILVA SÁNCHEZ, en este delito la solidaridad no es el bien juridico protegido, sino que los determinados bienes personales que el propio articulo indica - art. 195 CP español-. La vulneración de este deber de solidaridad constituye el título de imputación de la responsabilidad penal. Cfr. SILVA SÁNCHEZ, "Entre la omisión de socorro y la comisión por omisión. Las estructuras de los art. 195.3 y 196 del Código penal" en: Problemas específicos de la aplicación del Código penal. Manuales de formación continuada 4, 1999, p. 158. Sobre el rol axiológico de la solidaridad en el ordenamiento jurídico, cfr. BALDÓ LAVILLA, Estado de necesidad y legítima defensa, Barcelona, 1994, p. 43 y ss. También se ha discutido en España si en el delito de omisión del deber de intervenir para impedir determinados delitos - Art. $450 \mathrm{CP}$ - el bien jurídico protegido es la solidaridad. Al respecto, cfr. SOLA RECHE, La omisión del deber de intervenir para impedir determinados delitos del art. 450 CP. Granada, 1999, p. 30 y ss.

Sentencia de la Excma. Corte Suprema de 4 de agosto de 1998. En el considerando $13^{\circ}$ expone: "Que, en primer lugar, conviene señalar que, prescindiendo de algunas reservas sobre la constitucionalidad de hacerlo - las cuales no deberian ser desoídas en modo alguno por el legislador en relación con una futura reforma penal- existe un amplio acuerdo en que los delitos comisivos - vale decir, aquellos cuyo tipo los describe como una actividadusualmente pueden cometerse también mediante una omisión. Ello es tanto más así, cuando el artículo $1^{\circ}$ inciso $1^{\circ}$ del Código penal deja establecido expresamente que los delitos pueden consistir tanto en una "acción" como en "omisión", en el inciso $2^{\circ}$ insiste en ello y el artículo $2^{\circ}$ declara que tanto los delitos dolosos como los imprudentes (cuasidelitos) pueden ser ejecutados en cualquiera de sus formas". Esta sentencia ofrece muy interesantes reflexiones sobre materias que han generado importantes discusiones a nivel teórico. En efecto, en ella el Alto Tribunal otorga eficacia excusante al error de prohibición, para luego considerar que en el caso sub-lite se configura un supuesto de comisión por omisión, sobre la base de que el procesado se hallaba en posición de garante respecto de la vida del occiso, dado que con su conducta anterior había creado el riesgo que amenazó la vida de otra persona. Si bien, reconozco que no es el momento ni el espacio para examinar la sentencia en comento, quisiera, brevemente, dar a conocer mis apreciaciones sobre lo expuesto por el voto de mayoría, acerca 
Cabe preguntarse, ¿el porqué de estos reparos? ¿Cuál es la razón de estas advertencias?

Un importante sector doctrinal ha manifestado que las objeciones a partir del principio de legalidad se presentarían desde el momento en que buena parte de los tipos penales describen procesos físicos de causación de resultados; esto es, se construyen sobre la base de una comisión activa ${ }^{5}$, en los que no podrían comprenderse las omisiones. Se trataría pues, de normas prohibitivas. Por tanto, habría que partir afirmando - conforme a lo expuesto supra- que no podrían incriminarse comportamientos en los que falta un movimiento corporal de orden causal, sin que ello pueda significar aplicar supuestos de analogía in malam partem ${ }^{6}$.

Ahora bien, como la mantención de este criterio - puramente causal naturalístico- puede llevar a extremos poco aconsejables, ya que existen omisiones que son claramente delictivas — clásico es el ejemplo, que viene de la Edad Media, de la madre que deja de alimentar a su hijo y éste muere-, la doctrina ha procurado elaborar construcciones que permitan salvar estas objeciones. Empero, siempre manteniendo la premisa de que se está frente a tipos penales activos. Pues bien, dada la imposibilidad de afirmar que la omisión "causa" un resultado determinado — sólo un hacer causa un cambio en el mundo exterior- se ha afirmado que en estos supuestos lo

de la improcedencia de la legítima defensa. En el fallo se consideraba que no era posible la configuración de la eximente al no concurrir el requisito basal, a saber, la agresión ilegítima. Se estimaba que la agresión era sólo aparente - el arma del occiso al tener el seguro puesto no podía representar ningún peligro para el bien jurídico agredido-, por tanto, objetivamente inidónea. A mi modo de ver, la conducta del occiso, de apellido Vallejos, sí era constitutiva de agresión legítima, generadora de una necesidad de defensa. Los hechos de autos así lo demuestran, pues Vallejos salió en persecución del hijo del procesado, para luego apuntarle con su arma, con lo cual la actualidad de la agresión es indiscutible, toda vez que el peligro generado hacía inaplazable una actuación defensiva. Sin embargo, es esencialmente la apreciación que se hace de la realidad la que determinó que el sentenciador resolviera la improcedencia de la legítima defensa. Es así, que en el cons. $3^{\circ}$ indica que la agresión fue sólo aparente, pues, al estar el arma de Vallejos con el seguro puesto no podía disparar y, en consecuencia, no se presentaba ningún peligro objetivo. Según mi parecer, los hechos al ser valorados desde una perspectiva ex ante sí ponen de manifiesto una objetiva peligrosidad en la intervención del occiso. En efecto, que se haya puesto el seguro en el arma no es óbice para apreciar una agresión real, toda vez que el arma sí tenía una capacidad objetiva de ser disparada y con ello de poner en peligro el bien jurídico. Aún en esas condiciones es lo suficientemente idónea para realizar una actividad lesiva, pues está dentro de la esfera de dominio del agresor el sacar el seguro y disparar. Como lo hace ver el voto de minoría, en el cons. $3^{\circ}$, el seguro de un arma es un objeto muy pequeño, que no requiere de grandes maniobras para sacarlo y dejar el arma en condiciones de ser disparada, sin que todo ello pudiera ser apreciado por el defensor. En definitiva, creo que valorado ex ante sí se estaba frente a un comportamiento agresivo, objetivamente idóneo para crear un peligro jurídico penalmente relevante, todo lo cual permite la configuración de la legítima defensa. Sobre el examen dogmático de la sentencia, cfr. SOTO PIÑEIRO, "Una jurisprudencia histórica: hacia el reconocimiento del "principio de culpabilidad" en el Derecho penal chileno" en: Revista de Derecho de la Universidad Finis Terrae, Año III, n 3, 1999, p. 233 y s5; SALIMHanna Sepúlveda, "Comentario de Sentencia" en: Revista de Derecho de la Universidad Finis Terrae, Año II, $n^{\circ}$ 2,1998, p. 24 y ss.

5Entre otros, cfr. POLITOFF, Derecho penal, T. I. Santiago, 1997 p. 310; Bustos RamíREZ, Manual de Derecho penal, PG, $4^{\circ}$ ed., Barcelona, 1994, p. 410. Vid. asimismo, NovOA MONREAL, Fundamentos de los delitos de omisión, Buenos Aires, 1984, p. 179 y ss.

${ }^{6} \mathrm{Para}$

Para mayor detalle, cfr. SILVA SÁNCHEZ, El delito de omisión. Concepto y sistema, Barcelona, 1986, p. 359 y ss. 
que se infringe es un mandato, al que están obligados ciertos sujetos en cuanto a impedir determinados resultados. Por lo tanto, lo que se incumple es un deber cualificado de evitación. El fundamento de la imputación se halla pues, en que el sujeto, si bien no ha causado ese resultado, se considera que sí lo ha hecho, por no haberlo evitado pudiendo, dada la posición en que se encontraba. Lo que se castiga es entonces, la infracción de un deber de evitación de un resultado ${ }^{\top}$.

Son los llamados por algunos tipos preceptivos de garante. Por ejemplo, si bien el sujeto activo "no mata", es decir, no se realiza el tipo escrito — de fundamento causal- se le castiga sobre la base de un tipo no escrito, "como si matase", por cuanto su infracción al deber de evitación tiene el mismo disvalor como el matar activamente ${ }^{8}$.

A mi modo de ver, este tipo de elaboraciones lesiona el principio de legalidad, pues la infracción del deber de evitación o, dicho en otros términos, la no ejecución del acto que impediría el resultado típico no se encuentra expresado en la ley. No es posible cimentar la punición en los términos expuestos, pues tales comportamientos no realizan los tipos que exigen un resultado ${ }^{9}$. En definitiva, la única referencia que existe entre el tipo prohibitivo y la norma de mandato es que dicen relación al mismo bien jurídico y emplean el mismo marco penal, pero, en lo demás, no se presentan mayores conexiones $^{10}$. Me parece claro que, así señalado, se estaría aplicando una disposición penal para sancionar conductas que no se hallan comprendidas en ella. En consecuencia, el que se castigue la omisión del deber de evitación de un resultado típico aplicando para ello tipos no escritos, mas relacionados con los tipos previstos en el ordenamiento, supone sí incurrir en la analogía contra reo, que como es sabido, está prohibida $^{11}$.

\footnotetext{
'Así, claramente, ETCHEBERRY, Derecho penal, PG, T. I, $3^{\circ}$ ed. Santiago, 1998, p. 203: "...tales conductas deben ser sancionadas como abandono o incumplimiento grave de deberes más que como la "causación" de un resultado" (Subrayado en el original); GARRIDO MONTT, Derecho penal, PG, T. II, Santiago, 1997, p. 186-187; CURY, Derecho penal.... II. p. 301, señala que lo que se imputa en esta clase de delitos es no haber evitado la lesión por quien tiene el deber de hacerlo. En su momento, BUSTOS/FLISFISCH/POLITOFF, "Omisión de socorroy homicidio por omisión", en: Revista de Ciencias Penales, T. XXV, n³ 3, 1966, p. 171. 8

Sobre esta clase de construcciones dogmáticas, cfr. GRÜNWALD, "Zur gesetzlichen Regelung der unechten Unterlassunsgdelikte", en: Zeitschrift für gesamte Strafrechtswissenchaft 70 (1958), p. 412 y ss.; asimismo, SILVA SANCHEZ, El delito de omisión.... p. 363.

Incluso, el propio GARRIDO MONTT, Derecho penal..., II, p. 186 asi lo asevera: "esta infracción del deber de ejecutar la acción no se encuentra expresada por la ley tipificada y sólo por vía interpretativa se homologa a la actividad productora del resultado típico, que sí está descrita por el legislador; BUSTOS RAMiREZ, Manual..., p. 410. también reconoce las vulneraciones al principio de legalidad que supone el recurso interpretativo.

${ }^{10}$ Al respecto, CFR. SILVA SÁNCHEZ, El delito de omisión...., p. 363.

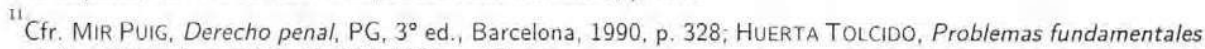
de los delitos de omisión, Madrid, 1987, p. 19 y ss.
} 
Conforme a lo expuesto, y dadas las discrepancias que emanan desde la perspectiva del principio nullum crimen nulla poena sine lege, un sector de la doctrina se manifiesta por la necesidad de establecer un sistema de numerus clausus. Esto es, que la ley especifique las omisiones punibles ${ }^{12}$. Sin embargo, esta propuesta no ha prosperado mayormente, debido a que establecerlas expresamente, hace que se trate de una solución impracticable por lo engorroso de ésta.

Dada las dificultades que presenta la postura anterior, otro sector teórico sostiene que la vía más pertinente para enfrentar los reparos que provienen del principio de legalidad es la de disponer una clá usula general que autorice la comisión por omisión de los delitos descritos en la Parte Especial. Supone pues, establecer presupuestos a través de los cuales es posible equiparar la omisión, el no impedir un resultado, con su causación activa $^{13}$.

Esta posición se ha expresado en los códigos penales de España ${ }_{18}^{14}$, Alemania ${ }^{15}$, Italia $^{16}$, Portugal ${ }^{17}$, Perú ${ }^{18}$, Colombia ${ }^{19}$ y Paraguay $^{20}$, entre otros.

\footnotetext{
${ }^{12}$ Asi, entre otros, HuerTA TOLCido, Problemas fundamentales..., p. 22, p. 163 y ss.; LA MiSMA, Principales novedades de los delitos de omisión en el Código penal de 1995, Valencia, 1997, p. 50 y ss.; POLITOFF, Derecho.... I, p. 313, aunque reconoce que es poco practicable; CURY, Derecho penal.... II, p. 295; SALIM-HANNA SEPÚLVEDA, "La constitucionalidad de los delitos de omisión impropia" en: Revista de Derecho de la Universidad Finis Terrae. AñoIV, $n^{\circ} 4,2000$, p. 78 .

13

Entre otros, cfr. MIR PUIG, Derecho..., $3^{\circ}$ ed., p. 329; ZUGALDIA ESPINAR, "Omisión e injerencia con relación al supuesto agravado del párrafo 3 del artículo 489 bis del Codigo penal", en: Cuadernos de Politica Criminal, 1984 p. 571 y ss; GÓmez Benitez, Teoría jurídica del delito, Madrid, 1987, p. 585; para, Bustos RAMiREz, Manual.... p. 412, la vía de la cláusula general le merecen reparos, estimando preferible el recurso del sistema de numerus clausus. Sin embargo, dada las complejidades que tal técnica manifiesta, cree que lo más adecuado es no legislar y dejarlo a la labor interpretativa; en su momento, esta vía también fue propuesta por MUÑOZ CONDE, en Su traducción de HASSEMER, Fundamentos del Derecho penal, Barcelona, 1984, p. 258; FIANDACA/MUSCO, Diritto penale, PG, $3^{\circ}$ ed., Bologna, 1995, p. 533-534. Conforme con la decisión adoptada para el CP español, CEREZO MIR, Curso de Derecho penal español, T. III, $1^{\circ}$ ed., Madrid, 2001, p. 261.

${ }^{14}$ A

Art. 11: "Los delitos o faltas que consistan en la producción de un resultado sólo se entenderán cometidos por omisión cuando la no evitación del mismo, al infringir un especial deber jurídico del autor, equivalga, según el sentido del texto de la Ley, a su causación. A tal efecto, se equiparará la omisión a la acción: a) Cuando exista una especial obligación legal o contractual de actuar. b) Cuando el omitente haya creado una ocasión de riesgo para el bien juridicamente protegido mediante una acción o una omisión precedente".

15

§13. Comisión por omisión: "(1) El que omite evitar un resultado que pertenece al tipo de una ley penal, será punible según esta ley sólo si tenía que responder juridicamente de que el resultado no se produjera y la omisión corresponde a la realización del tipo legal por un hacer. (2) La pena puede ser atenuada conforme a lo dispuesto en el § 49 , párr. $1 . "$

${ }^{16}$ Art. 40 cpv.: "No impedir un resultado que se tiene la obligación jurídica de impedir equivale a causarlo"

${ }^{17}$ Art. 10: Comisión por acción y por omisión: "1. Cuando un tipo legal de delito comprenda cierto resultado, el hecho abarca no sólo la acción adecuada para producirlo sino también la omisión de la acción adecuada para evitarlo, salvo que otra fuera la intención de la ley. 2. La comisión por omisión de un resultado sólo es punible cuando recaiga sobre el omitente un deber juridico que le obligue personalmente a evitar el resultado. 3 . En el caso del número anterior la pena podrá ser atenuada de modo especial"
} 
Ahora bien, como se ha subrayado precedentemente, las dos posturas recién expuestas, para dar una solución coherente desde la perspectiva del principio de legalidad, parten de la base de que se está frente a tipos penales que se construyen conforme a un hacer activo. Empero, hoy en doctrina se ha abierto una tercera posición para abordar el problema, que, según mi parecer, responde de mejor forma las dudas en torno a la máxima del nullum crimen nulla poena sine lege. $\mathrm{Y}$ es que no sería preciso recurrir al sistema de numerus clausus ni a una cláusula general para conciliar este principio con la comisión por omisión. Para ello, debe partirse de la siguiente premisa, que a continuación se desarrollará, y es que no hay razones para estimar que los tipos penales se construyen en un sentido causal-naturalístico.

Esta postura es la que ha sido sostenida, principalmente, por Silva Sánchez y también, aunque con algunos matices que las distinguen, por Mir Puig, Gracia Martín, Luzón Peña y Gimbernat, entre otros ${ }^{21}$.

Anteriormente, he subrayado que las tesis dominantes parten del supuesto de que gran parte de los tipos penales describen procesos de causación, esto es, se construyen sobre la base de un hacer activo. Conforme a lo anterior, pues, cabe hacerse

18

Art. 13. Omisión impropia: "El que omite impedir la realización del hecho punible será sancionado: 1. Si tiene el deber jurídico de impedirlo o si crea un peligro inminente que fuera propio para producirlo. 2. Si la omisión corresponde a la realización del tipo penal mediante un hacer. La pena del omiso podrá ser atenuada"

19

Art. 25: Acción y omisión. "La conducta punible puede ser realizada por acción o por omisión. Quien tuviere el deber jurídico de impedir un resultado perteneciente a una descripción típica y no lo llevare a cabo, estando en posibilidad de hacerlo, quedará sujeto a la pena contemplada en la respectiva norma penal. A tal efecto, se requiere que el agente tenga a su cargo la protección en concreto del bien jurídico protegido, o que se le haya encomendado como garante la vigilancia de una determinada fuente de riesgo, conforme a la Constitución o a la Ley. Son constitutivas de posiciones de garantía las siguientes situaciones: 1.- Cuando se asuma voluntariamente la protección real de una persona o de una fuente de riesgo, dentro del propio ámbito de dominio. 2. Cuando exista una estrecha comunidad de vida entre personas. 3.- Cuando se emprenda la realización de una actividad riesgosa por varias personas. 4,- Cuando se haya creado precedentemente una situación antijuridica de riesgo próximo para el bien jurídico correspondiente. Parágrafo. Los numerales 1, 2, 3 y 4 sólo se tendrán en cuenta en relación con las conductas punibles delictuales que atenten contra la vida e integridad personal, la libertad individual, y la libertad y formación sexuales"

20

Art. 15: Omisión de evitar un resultado: "Al que omita impedir un resultado descrito en el tipo legal de un hecho punible de acción, se aplicará la sanción prevista para éste sólo cuando:1. exista un mandato juridico que obligue al omitente a impedir tal resultado; y 2 . este mandato tenga la finalidad de proteger el bien jurídico amenazado de manera tan especifica y directa que la omisión resulte, generalmente, tan grave como la producción activa del resultado"

21

Cfr. Silva SÁNChez, El delito de omisión..., p. 359 y ss; EL MISMO, El nuevo Código penal: cinco cuestiones fundamentales, Barcelona, 1997, p. 59 y ss,; LUZÓN PEÑA, "La participación por omisión en la jurisprudencia reciente del TS" en: Estudios Penales, Barcelona, 1991, p. 234 y ss., en p. 235 expresamente discrepa que la equivalencia entre la actividad y la comisión por omisión se dé por la posición de garante; GRACIA MARTiN, "La comisión por omisión en el derecho penal español" en: La comisión por omisión. Cuadernos de Derecho judicial, Consejo General del Poder Judicial, Madrid, 1994, p. 57 y ss, en especial p. 73 y ss.; GIMBERNAT ORDEIG, "Causalidad, omisión e imprudencia" en: La comisión por omisión, Cuadernos de Derecho judicial, Consejo General del Poder Judicial, Madrid, 1994, p. 161 y ss.; MIR PUIG. Derecho..., $3^{\circ}$ ed., p. 329, señala que esta vía es posible si entendemos los verbos legales que exigen un resultado no en un sentido naturalístico, sino social; VIVES ANTÓN, en: VIVES (Coord), Comentarios al Código penal de 1995, Valencia, 1996, p. 84 y ss. 
la siguiente pregunta: ¿ Es posible estimar que los verbos típicos se limitan a describir procesos causales? Así, por ejemplo, el Art. 391 del Código Penal cuando dice: "el que mate a otro", ¿ sólo abarca a quienes hayan causado desde una perspectiva puramente naturalística el resultado muerte? $\mathrm{O}$, más bien, ¿ no estaría comprendiendo a quienes se les puede atribuir o imputar el resultado muerte?

Dichas preguntas también pueden formularse en otro sentido: los verbos que emplea la ley, ¿ tienen un sentido puramente descriptivo o tienen más bien un carácter adscriptivo o atributivo? ${ }^{22} \mathrm{Al}$ respecto, conviene tener en consideración que para el lenguaje ordinario o cotidiano los verbos típicos suponen algo más que describir un proceso causal y es el de atribuir responsabilidad por un determinado resultado. Como indica el propio Silva Sánchez, que todavía se sostenga que los tipos penales deben ser interpretados como construcciones descriptivas de un hacer activo, es fruto de la influencia que aún se manifiesta de la escuela clásica causalista ${ }^{23}$.

Conforme a lo anterior, cuando por ejemplo, se castiga al que mate a otro, el tipo penal no se limita a aquellos que causen la muerte, sino que está comprendiendo todos aquellos comportamientos a los que se les puede atribuir el resultado muerte ${ }^{24}$. Es decir, para el lenguaje cotidiano lo que se castiga es aquella actuación a la que le podamos adscribir aquel proceso que finalizó con la muerte de una persona, ya sea que lo haya causado físicamente o ya sea que no lo haya evitado pudiendo ${ }^{25}$. En consecuencia, desde la perspectiva del lenguaje ordinario, las omisiones también pueden producir un resultado. Nada obsta pues, que los verbos típicos puedan ser así comprendidos.

Es así, que en Alemania, Bottke se refiere a la "utilización crítica del lenguaje cotidiano" (methodik kritischer alltagssprachnützung) como una vía adecuada para resolver los problemas que son sometidos a la consideración de la dogmática penal. Para este autor el lenguaje cotidiano atesora una sabiduría idónea con relevancia penal que permitiría acceder a la comprensión del derecho. Es preciso, dice este autor, acudir

\footnotetext{
${ }^{22}$ Asi ya ha sido puesto de manifiesto por SILVA SÁNCHEZ, El nuevo Código penal..., p. 60-62. De modo similar, COBO/VIVES, Derecho penal, PG, $3^{\circ}$ ed. Valencia, 1991, p. 303, señalan que los verbos típicos no remiten como sustrato a una realidad puramente naturalística, sino a una realidad dotada de significación social.

${ }^{23}$ Cfr. Silva SánChez, El nuevo Código penal..., p. 61.

${ }^{24}$ Asi lo expone, SILVA SÁnCHEZ, El nuevo Código penal... p. 60; COBO/VIVES, Derecho penal..., $3^{\circ}$ ed., p. 303 : "Cuando, jurdídicamente, decimos que alguien ha matado, no queremos expresar con ello que ha realizado una acción positiva de la que, como consecuencia, derivase la muerte, sino que la muerte de otro es imputable objetivamente a su conducta. Y la muerte será imputable objetivamente a su conducta, tanto si el autor ha producido efectivamente el resultado dañoso, cuanto si, pese a ocupar una posición de garante, desde la que asumía la tutela del bien, ha dejado que se produzca". (La cursiva en el original).

${ }^{25}$

${ }^{5}$ Cfr. MiR PUiG, Derecho..., $3^{\circ}$ ed., p. 329.
} 
al lenguaje común —al análisis del sentido común — que se presenta como un recurso crítico para el sometimiento jurídico de los ciudadanos

Pues bien, habiendo llegado a este punto y a fin de hacer más clara la exposición, podemos resumir lo hasta ahora expuesto con un sencillo ejemplo: alguien se ahoga en una piscina y por ello se muere. Conforme a lo tratado precedentemente, es posible, en principio, entender que ese acto puede subsumirse dentro del Art. 391 del Código Penal, aun cuando nadie lo haya causado activamente. Queda entonces, por resolver, a quién de todas aquellas personas que estaban en ese momento alrededor de la piscina se le puede imputar, atribuir ese resultado. A continuación, trataré de explicar cómo se puede resolver este último punto.

Hay quienes sostienen que como la comisión y la omisión son ontológicamente distintas, no es posible elaborar una única construcción normativa típica que permita comprender, tanto el hacer activo como la falta de hacer. Ahora bien, es cierto que en el plano del ser, existen divergencias que no son posibles de conjugar ${ }^{27}$. Por lo tanto, la discusión no puede revolverse en este ámbito, sino que ésta debe llevarse a una esfera

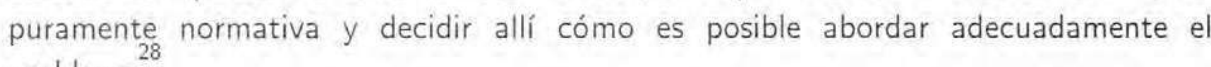
problema ${ }^{28}$.

Presentado así, hay que convenir que, tanto acción como omisión son modos de creación o de aumento de riesgos típicos sobre un determinado bien jurídico. Esto es, entre ambos — comisión y omisión- existe una identidad en cuanto son títulos de imputación un resultado. Ambos son medios que permiten ejercer un control sobre ciertos riesgos típicos. Apreciado así, entre la comisión activa y la comisión por omisión es posible hallar una identidad, tanto estructural como material, en cuanto ambos son,

\footnotetext{
${ }^{26}$ Cfr. BOTTKE, "Estructura de la autoría en la comisión y en la omisión como requisito para la construcción de un sistema de Derecho penal de la Comunidad Europea", (trad. M. Corcoy Bidasolo) en: SILVA SÁnCHEZ (Ed.), Fundamentos de un sistema europeo de Derecho penal. Libro-Homenaje a Claus Roxin. Barcelona, 1995, p. 310 y ss. Para mayor detalle, vid. BOTTKE, Täterschaft und Gestaltungsherrschaft. Zur Struktur von Täterschaft bei aktiver Begehung und Unterlassung als Baustein eines gemeineuropaischen Strafrechtssystems, Heildelberg. 1992.

27

Gracia Martín, "La comisión por omisión...", p. 75; Silva Sanchez, El nuevo Código penal..., p. 62; Cerezo MIR, Curso de derecho penal español, PG, T. II, $5^{\circ}$ ed., Mdrid, 1997, p. 44 y ss. Para JAKOBS, "La competencia por organización en el delito omisivo", en: Estudios de Derecho penal, (trad. Peñaranda Ramos/Suárez González/Cancio Meliá), Madrid, 1997, p. 346 y ss., la distinción entre comisión y omisión es superficial, dado que en ambos el fundamento de la responsabilidad se halla en la transgresión de las reglas del status general, e que viene determinado por el derecho que tiene cada uno a configurar libremente la organización dentro de los márgenes del riesgo permitido y por el deber de evitación de riesgos cuando se superan esos márgenes. Así, un autor en comisión activa es siempre garante en lo que a su propia organización respecta y un autor por omisión es siempre garante del out-put de su organización. Lo decisivo no será pues, la clase de conducta realizada, sino la atribución o no del daño a la organización del autor.

${ }^{28}$ Para CEREzo Mir, Curso..., T. III, $1^{\circ}$ ed., p. 254, el concepto de omisión no es un concepto puramente normativo. pues la respuesta de si un sujeto no llevó a cabo la acción pudiendo realizarla, puede hallarse en un juicio puramente objetivo, sin tener que realizar alguna clase de valoración.
} 
reitero, mecanismos que permiten realizar un control para la evitación de determinados peligros de relevancia jurídico-penal ${ }^{29}$.

Los tipos penales lo que prohiben son aquellos comportamientos que suponen crear o aumentar un riesgo sobre un determinado bien jurídico, ya sea que estos riesgos provengan por actos — causalidad activa - o por quien habiendo asumido como barrera de contención o evitación de riesgos sobre cierto bien jurídico ajeno, no actúa, incumpliendo así un compromiso ya adquirido y que conlleva la creación del riesgo típico $^{30}$. En consecuencia, aun cuando ese riesgo no haya sido creado directamente por el sujeto, desde el momento que asume como barrera de contención y vulnera ese compromiso, poniendo en peligro ese bien jurídico, debe asumir - desde una perspectiva normativa - los riesgos que su comportamiento ha creado, como si los hubiera creado. Así pues, quien activamente crea un riesgo típico tiene el control de evitación del resultado. Del mismo modo, quien vulnera su compromiso de evitacion del riesgo típico, está creando ese riesgo, es decir, si bien no lo está originando causalmente, al constituirse en salvaguarda del bien jurídico ajeno, genera en el sujeto un dominio sobre ese riesgo, similar a quien lo crea activamente. Conforme a lo anterior, quien omite un acto, que nace de su compromiso o de su deber de garante, está infringiendo éste, y con ello, con su omisión, está entrometiéndose en la esfera jurídica ajena, creando sobre él un riesgo típicamente relevante ${ }^{31}$. Respecto de este último supuesto, también se realiza el tipo penal.

Así, cuando la norma primaria dice: "se prohibe matar", ¿qué se esta prohibiendo? La realización de todos aquellos comportamientos que pueden devenir en la creación riesgos típicamente relevantes, que supongan una injerencia en el bien jurídico vida ajena, ya sea que éstos se creen por vía de un hacer activo o a través de una vulneración de su compromiso o deber de garante, desencadenando así, el riesgo sobre el bien jurídico. Se le imputa entonces la causalidad del riesgo no creado activamente.

Hemos visto pues, de conformidad a las premisas expuestas, que desde una perspectiva normativa no habría dificultad para conciliar el hacer activo y el no hacer, si estimamos que ambas, repito, son formas de control de riesgos típicos. Ahora bien, a lo largo de la exposición, tratándose de la comisión por omisión, hemos hablado de la existencia de un deber de evitación, esto es, el de constituirse en barrera de contención respecto de determinados riesgos que pueden recaer sobre algún bien jurídico. Es lo que tradicionalmente se conoce como la posición de garante.

\footnotetext{
${ }^{29}$ En estos términos, Gracia MARTín, "La comisión por omisión...", p. 75-76; Silva SÁnChez, El nuevo Código penal..., p. 62; LuZÓN PEÑA, Estudios..., p. 235 y ss.

${ }^{30}$ Silva SánCHez, El nuevo Código penal..., p. 62-63.

${ }^{31}$ Asimismo, Silva SÁnCHez, El nuevo Código penal..., p. 63.
} 
Sin entrar a precisar cada una de éstas, sólo me limitaré a señalar que hoy en la doctrina, para determinar los deberes cualificados de evitación de resultados, se están imponiendo las tesis que fundamentan la posición de garante en la relación de orden material que se manifiesta entre el bien jurídico y el sujeto - teoría de las funciones32. Apartándose así, de las llamadas tesis formalistas - v. gr. las que emanan de la ley, el contrato, la injerencia-, que por su rigidez no otorgan una respuesta adecuada a este problema ${ }^{33}$.

Precisamente, conforme a estas propuestas materiales, dos son los caminos para precisar que a la omisión de un sujeto se le puede atribuir un resultado típico, a saber, los que dicen relación a la función especial de protección de un bien jurídico -así, vínculo familiar estrecho, comunidad de peligro y asunción voluntaria-y aquellos que guardan relación con una función especial de control de fuentes de peligro -así, injerencia, control de peligros se encuentran en el propio ámbito de dominio y deberes de control respecto de la conducta de terceros- Reconozco que este tema merece una extensión mayor, pero al menos lo dejo esbozado.

No obstante lo expuesto, si bien es esencial para estructurar un supuesto de comisión por omisión que un sujeto se encuentre en una posición de garante, este requisito no es el determinante. Esto es, puede acontecer que un sujeto se halle en esta posición $y_{1}$ sin embargo, no responda por el resultado lesivo respecto de un determinado bien jurídico. Dicho en otros términos, la presencia de un deber específico de evitación de un resultado no es aún suficiente para estar frente a un supuesto de comisión por omisión ${ }^{34}$. Puede acontecer pues, que su omisión no sea equivalente

\footnotetext{
${ }^{32}$ Como es sabido, esta propuesta procede de los trabajos de Armin Kaufmann, principalmente en Die Dogmatik der Unterlassungsdelikte, Göttingen, 1959. Al respecto, Cfr. MAURACH/GÖSSEL/ZIPF, Derecho penal, PG, T. II, (trad. J. Bofill Genzsch), Buenos Aires, 1995, p. 248 y ss.; MIR PUIG, Derecho penal, PG, $5^{\circ}$ ed., Barcelona, 1998, p. 305 y ss.; BuStos RAMirez, Manual..., p. 412 y ss.; si bien, partiendo de una perspectiva material, desarrolla una propuesta distinta, JAKOBS, Derecho penal, PG, (trad. J. Cuello Contreras/J. Serrano González de Murillo), Madrid, 1997, p. 970 y ss. Cfr. la exposición que sobre el tema hace CUADRADO Ruiz, "La posición de garante", en: Revista de Derecho penal y criminología, $n^{\circ} 6,2000$, p. 11 y ss.

${ }^{33}$ Sin embargo, el CP español, en su Art. 11. hace una referencia a esta teoría formal. Crítico a este criterio, CEREZo MiR, Curso... T. III, $1^{\circ}$ ed., p. 263. Asimismo, el CP italiano - Art. $40 \mathrm{cpv}$.- al hablar de una obligación jurídica. Pero, se ha ido produciendo en la jurisprudencia italiana una evolución que tiende a incluir otras fuentes de contenido material, cfr. FIANDACA/MUSCO, Diritto.... p. 545 y ss.; CARACCIOLI, Manuale di Diritto penale, PG Padova, 1998, p. 273 y ss. En Chile, parecieran aún predominar las posturas formalistas, cfr. ETCHEBERRY, Derecho penal.... p. 205-207; CURY. Derecho penal..., II. p. 296 y ss.; POLITOFF, Derecho..., I, p. 315 y ss.; crítico a las propuestas materiales, pues pueden dar lugar a una excesiva extensión de las fuentes, NOVOA MONREAL, Fundamentos.... p. 145-146.

${ }^{34}$ A

Así también lo deja planteado, SOTO PIÑEIRO, "Una sentencia histórica...", p. 253; en este sentido, MIR PUIG Derecho..., $5^{\circ}$ ed., p. 309-310, señala que no es suficiente que concurran las relaciones familiares para que la inactividad constituya comisión por omisión. Es preciso además, que la situación de absoluta dependencia personal que caracteriza a la posición de garante se produzca en el caso concreto. Sin embargo, la sentencia de la Corte Suprema a la que se ha hecho referencia supra $(n, 4)$, deja entrever que la configuración de una posición de garante hace que necesariamente el título de la imputación sea comisión por omisión.
} 
material y normativamente a la producción del resultado por comisión activa ${ }^{35}$. Es lo que en doctrina se denomina omisión pura de garante o también omisión de gravedad intermedia. Se trata pues, de omisiones que son más graves que las omisiones puras así, la omisión de socorro- pero, no tienen la misma valoración negativa que permitan configurar un supuesto de comisión por omisión: es decir, como afirma Silva Sánchez, su desvalor no es el propio de la comisión activa, de forma tal, que permitan estimarlas idénticas -estructural y materialmente-a ésta ${ }^{36}$.

Un ejemplo puede llegar a clarificar lo expuesto. El médico de urgencia recibe un paciente que ha sufrido un accidente de tránsito y por ello se encuentra en peligro grave de muerte. Si bien, el médico tiene un deber cualificado de evitación de un determinado resultado - en este caso, impedir la muerte-, que nace por su asunción voluntaria, se trata de un deber genérico que surge al asumir el servicio de urgencias. Su asunción no es suficiente para estimar que se ha constituido en barrera de contención frente a ciertos riesgos típicos, de manera que interrumpe el surgimiento de otros cursos causales salvadores. Por tanto, en este caso particular si acontece la muerte del paciente, su omisión no puede estimarse idéntica a cómo si la hubiera causado activamente. Cosa distinta es si el médico al constituirse en barrera de contención, de él depende el acontecer típico, esto es, si retira el curso causal salvador se materializa el riesgo típico sobre el bien jurídico. En este caso, sí puede estimarse su omisión como estructural y normativamente equivalente a su causación activa. Se aprecia pues, que se está frente a algo más que una omisión de socorro, pero también a algo menos que a una comisión por omisión.

No me voy a detener en esta nueva estructura, pues recién la doctrina se está abriendo a estos planteamientos, pero, tal como ésta ha señalado, su expresa tipificación permitiría contemplar supuestos en los que la pena de la omisión de socorro puede ser escasa y la sanción para la comisión por omisión excesiva. Es decir, de lege ferenda al estructurarse estas figuras "intermedias" permitiría al juzgador no tener que imputar a título de comisión por omisión ante la baja penalidad de la omisión pura, con el consiguiente peligro que se genere una expansión de aquellos supuestos ${ }^{37}$. Al respecto, no debe olvidarse que una de las tendencias de las sociedades modernas llamadas también sociedades del riesgo - es la de ampliar los supuestos de imputación

\footnotetext{
${ }^{35}$ Esencial resulta la obra de SILVA SÁNCHEZ, El delito de omisión.... p. 334 y ss., y particularmente 344 y ss.; EL MISMO, El nuevo Código penal..., p. 70-74.; GRACIA MARTín, "La comisión por omisión...", p. 88 y ss.; LuzÓN PEÑA, Estudios..., p. 242; ya intuida por RoXIN, Política criminal y sistema del Derecho penal, (trad. F. Muñoz Conde), Barcelona, 1972, p. 47.

${ }^{36}$ Cfr. Silva SÁnChez, El nuevo Código penal..., p. 71.

${ }^{37}$ Los Art. 195.3 y 196 del CP español recogen supuestos de omisiones de gravedad intermedia.
} 
a título de comisión por omisión, es por ello debe obrarse normativamente con cuidado $^{38}$.

\section{Conclusiones}

A modo de recapitulación, para la comisión por omisión se requiere pues, de que un sujeto se encuentre en posición de actuar, esto es, que haya asumido un compromiso de actuación, de que evitara los riesgos típicos que pueden recaer sobre algún bien jurídico. Es decir, debe estarse frente a un doble compromiso: positivo, en cuanto a que este compromiso supone una mayor protección al bien jurídico, hay una asunción frente a la sociedad de que se hará cargo y negativo, en cuanto a que la misma sociedad no prestará mayores resguardos al haber alguien asumiendo esa función. Esto es, se genera una interrupción de otros cursos causales salvadores.

Este compromiso supone entonces, que habrá alguien que controla los riesgos típicos, quien al tener el dominio sobre el curso causal con su actuación impedirá que determinados riesgos se materialicen y lesionen un determinado bien jurídico. Su omisión, en este sentido, será equivalente materialmente a como sí hubiera causado activamente ese resultado. El sujeto tiene un compromiso de actuación y no lo hace, lo que deviene luego en un resultado típico.

Pues bien, como la perspectiva de análisis es normativa y no naturalística es perfectamente posible atribuir un determinado resultado a una omisión. Desde una esfera normativa es idéntico crear activamente ese riesgo, que estar frente a un riesgo, tener él deber de controlarlo — pudiendo claro está-, y luego no hacer nada al respecto, permitiendo que ese riesgo efectivamente lesione el bien jurídico,

Espero que lo expuesto haya permitido conocer cuáles son las discusiones que hoy se plantean en la dogmática en torno a la comisión por omisión. Indudablemente, el tema es bastante más complejo y más vasto de lo que aqui se ha planteado, pero, aun así, espero haber podido dar a conocer cuáles son los lineamientos teóricos más relevantes.

\footnotetext{
${ }^{38}$ Si bien el avance de la tecnología ha dado lugar a un mayor bienestar de la población también ha incrementado los riesgos a que ésta se expone, la que, por regla general, no ha participado en su generación. Además, como han aumentado las actividades interdependientes, la protección de los intereses de cada individuo deberá depender de lo que realicen otros individuos. Se trata pues, de riesgos globales, los que muchas veces provienen por actos imprudentes o por lo que se ha dejado de hacer. Cfr., por todos, BECK. La sociedad del riesgo, (trad. J. Navarro/D. Jiménez/M. R. Borrás), Barcelona, 1998, passim. Asimismo, cfr. SIlva SÁnChEz, La expansión del Derecho penal, $2^{\circ}$ ed., Madrid, 2001, p. 45; MENDOZA BUERGO, El Derecho penal en la sociedad del riesgo, Madrid, 2001, p. 95
} 